\title{
Complex Regulatory Interplay Between Multidrug Resistance and Oxidative Stress Response in Yeast: The FLR1 Regulatory Network as a Systems Biology Case-Study
}

\author{
Miguel C. Teixeira' ${ }^{1,2}$ \\ ${ }^{1} I B B$ - Institute for Biotechnology and Bioengineering, \\ Centre for Biological and Chemical Engineering, \\ Instituto Superior Técnico, Lisboa, \\ ${ }^{2}$ Department of Bioengineering, \\ Instituto Superior Técnico, \\ Technical University of Lisbon, Lisboa, \\ Portugal
}

\section{Introduction}

Multidrug resistance (MDR), the intrinsic or acquired ability to tolerate toxic concentrations of structurally and functionally diverse chemicals, is a widespread phenomenon that can be found in all living organisms, from bacteria to man (Hayes and Wolf 1997). Its negative consequences include the failure of many therapeutic, antimicrobial and crop protection actions. At the same time, the ability to tolerate multiple stresses is a highly desirable phenotype in organisms used as cell factories that have to cope with fermentation-related stresses (Teixeira et al. 2011b). It is, thus, crucial to understand the molecular basis underlying this phenomenon to be able to circumvent it or to explore it to design more robust industrial strains.

Oxidative stress, on the other hand, is usually considered the result from an imbalance between the generation or influx of reactive oxygen species and the cell ability to readily neutralize these molecules (Ikner and Shiozaki 2005; Lushchak 2011). Increased ROS concentration may lead, in term, to the modification of susceptible biomolecules, such as [Fe-S]-clusters-containing enzymes, proteins exhibiting reactive thiol groups, DNA and lipids, which may undergo peroxidation. These corrupted molecules may, in a small number of cases, be regenerated, but in most cases are degraded or accumulated in cells. The steady-state accumulation of ROS and associated ROS-damaged biomolecules has been linked to ageing and to the development of certain pathologies, such as diabetes mellitus, atherosclerosis and cardiovascular and neurodegenerative diseases (Lushchak 2011). Oxidative stress is usually linked to cell exposure to reactive oxygen species, including hydrogen peroxide, or to redox-cycling agents such as menadione, which leads to superoxide radical generation. However, mounting evidence appears to suggest that many 
chemical compounds, including widely used pesticides and pharmaceuticals, can induce oxidative stress indirectly, acting as pro-oxidant agents, at the same time that drug resistance mechanisms are activated. The comprehension of the underlying molecular mechanisms is, thus crucial to evaluate the toxicity of these xenobiotics and to design strategies to deal with the arising of multidrug resistance.

Being now clear that these cellular protection programs, crucial to prevent or delay disease progression and ageing, are highly interconnected, it is pivotal to fully understand the underlying cross-mechanisms. Thus, this chapter integrates current knowledge of the link between oxidative stress and multidrug resistance transcriptional control in S. cerevisiae, extending it to pathogenic yeasts. The particular case of the regulation of the multidrug resistance transporter Flr1 is further explored as an example of the use of systems biology approaches, including the combination of experimental and computational techniques, to increase our understanding of complex regulatory networks, shedding light into the crosstalk between the MDR phenomenon and oxidative stress response.

\section{The multidrug resistance network in yeast}

Multidrug resistance is often acquired through the activation of multidrug efflux pumps, belonging to the ATP-Binding Cassette (ABC) or Major Facilitator Superfamilies (MFS), this activation occurring, many times, at the transcriptional level. This fact has led to years of research aiming the definition of the transcription regulatory networks that control the expression of multidrug transporters under stress. The first finding in this field was the discovery that the PDR1 gene (Saunders and Rank 1982), latter characterized as a transcription factor (Balzi et al. 1987), confers multidrug resistance in the model eukaryote $S$. cerevisiae. Soon after, the so-called PDR (Pleiotropic Drug Resistance) network was first described (Balzi and Goffeau 1995) as a very simple network in which Pdr1, and its homologous transcription factor Pdr3, were found to control the transcription of the PDR5 gene (Balzi et al. 1994), encoding an ABC drug efflux pump. This network was rapidly extended to include other ABC multidrug transporters, such as Snq2 (Decottignies et al. 1995), but also members of a new family of multidrug transporters of the MFS (Sá-Correia et al. 2009), predicted to function as Drug: $\mathrm{H}^{+}$Antiporters (DHA) and uncovered mostly upon the release of the $S$. cerevisiae genome sequence (Goffeau et al. 1996), including Flr1 (Brôco et al. 1999; Tenreiro et al. 2001) and Tpo1 (do Valle Matta et al. 2001; Teixeira and Sá-Correia 2002). The use of genome-wide expression analysis tools helped to enlarge this network, while the genome-wide targets of Pdr1 and Pdr3 were uncovered (DeRisi et al. 2000). Apparently, several unrelated drugs and xenobiotics are able to bind to the so-called xenobiotic-binding domain of Pdr1p family members in budding yeast and in the human pathogen Candida glabrata, resulting in the over-expression of drug efflux pumps, this finding, providing new clues for the development of novel targets for antifungal drugs (Thakur et al. 2008). Additionally, new transcription factors were also found to belong to the PDR network, based on their homology to Pdr1 and Pdr3. These include Yrr1 (Le Crom et al. 2002), Pdr8 (Hikkel et al. 2003) and Yrm1 (Lucau-Danila et al. 2003), their target-genes also being identified through microarray analysis and, more directly, through ChIP(Chromatine ImmunoPrecipitation)-on-chip analysis. Considering only the canonical PDR transcription factors and the genes encoding predicted multidrug transporters of the $\mathrm{ABC}$ and MFS superfamilies, we get a relatively small, but intricate network controlling 
multidrug resistance in S. cerevisiae, as depicted in Fig. 1. However, if we consider all the targets of the same five transcription factors, the PDR network is found to include nearly 500 target genes with a broad scope of biological functions.
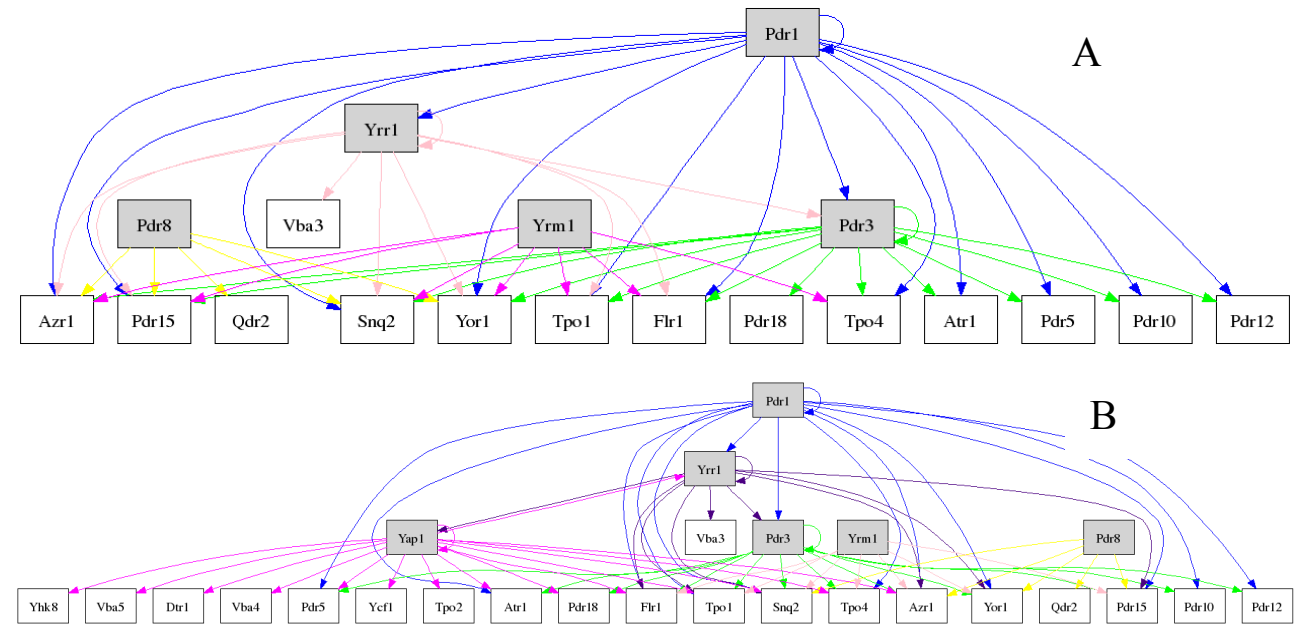

Fig. 1. A: The PDR network, considering only the canonical PDR transcription factors and the genes encoding predicted multidrug transporters of the ABC and MFS superfamilies. B: The PDR network, considering the canonical PDR transcription factors, the oxidative stress response regulator Yap1, and the genes encoding predicted multidrug transporters of the $\mathrm{ABC}$ and MFS superfamilies. Both networks were built based on the information gathered in the YEASTRACT database (www.yeastract.com), considering as evidence for transcriptional association between transcription factor and target genes either expression and/or DNAbinding evidence.

Further extending this network, it became clear that other transcription factors, whose function is not primarily linked to multidrug resistance, are also involved in the transcriptional control of drug efflux pumps. The first non-PDR transcription factor to join this network was Yap1, the major regulator of oxidative stress response in yeast (RodriguesPousada et al. 2010), found to confer resistance to the drug diazaborine via the Pdr3 and, less significantly, Pdr1 transcription factors (Jungwirth et al. 2000; Wendler et al. 1997). Two other transcriptions factors found to relate to the PDR network are Rpn4 (Owsianik et al. 2002; Teixeira et al. 2008) and Hsf1 (Hahn et al. 2006), regulators of proteasomal genes and of the heat shock response, respectively.

\section{The role of yap1 in multidrug resistance in yeast}

Recent studies in this field focusing the model eukaryote Saccharomyces cerevisiae have shown that there seems to be a close cross-talk between the multidrug resistance regulatory network and the oxidative stress response transcription factor Yap1. Indeed, Yap1 was demonstrated to confer resistance against a wide variety of drugs, including quinine, rapamycin, trenimon and diazaborine, but also to antifungal agents, such as cerulenin, 
benomyl, cycloheximide, fenpropimorph, mancozeb, to herbicides, including sulfometuron methyl, 2,4-dichlorophenoxyacetic acid (2,4-D) and paraquat and to the food preservative acetic acid. Although some of these compounds have been described as pro-oxidants molecules (Dias et al. 2010; Semchyshyn et al.; Teixeira et al. 2004), the role of Yap1 in drug resistance seems to rely not only in the control of antioxidant defenses, but also on the control of multidrug resistance transporters. In fact, Yap1 has been shown to underlie the stress-induced up-regulation of the multidrug ABC transporters Pdr5, Pdr18, Snq2, and Ycf1 (Cabrito et al. 2011; Jungwirth and Kuchler 2006; Teixeira et al. 2006) and of the drug: $\mathrm{H}^{+}$ antiporters Atr1, Azr1, Dtr1, Flr1, Qdr3, Tpo1, Tpo2, Tpo4, and Yhk8 (Sá-Correia et al. 2009; Teixeira et al. 2011a) (Table 1). If we take a global look, it becomes clear that the role of Yap1 in the regulation of the PDR network is even broader. Indeed, using the YEASTRACT database, a repository of all demonstrated regulatory associations in $S$. cerevisiae (Abdulrehman et al. 2011; Monteiro et al. 2008; Teixeira et al. 2006), it is possible to see that Yap1 co-regulates around 18\% of the Pdr1-target genes (Fig. 2A).

Interestingly, Yap1 displays two different activation mechanisms depending on the nature of the imposed stress. In both cases, the molecular events triggering Yap1 activation are apparently responsible for releasing this transcription factor from the interaction with the exportin Crm1, thus leading to its nuclear accumulation (Yan et al. 1998). One of the activation mechanisms occurs due to the increase in intracellular ROS concentration, due, for example, to cellular exposure to $\mathrm{H}_{2} \mathrm{O}_{2}$. Hydrogen peroxide appears to, indirectly, lead to the formation of an intramolecular disulfide bond between Cys303 and Cys598 of Yap1 (Delaunay et al. 2000). On the other hand, a second redox centre was later found in this transcription factor, and suggested to involve the direct binding of electrophiles such as Nethylmaleimide (Azevedo et al. 2003) to Cys598, Cys620 and Cys629, thus inducing a conformational change that also prevents Yap1-Crm1 binding and, thus, leads to Yap1 accumulation in the nucleus. Given this differential activation mechanism, the question of whether Yap1 could regulate distinct target-gene sets under different stress conditions arose.

Microarray analysis was recently used to compare the Yap1-dependent transcriptional response to hydrogen peroxide and to the thiol-reactive compounds N-ethylmaleimide (NEM) and acrolein (Ouyang et al. 2011). The obtained results showed that 56 genes are exclusive of the response to $\mathrm{H}_{2} \mathrm{O}_{2}$, while 327 are exclusive of the response to NEM or acrolein. Although both responses were primarily under the control of the same transcription factor, in each case the elicited response resulted in the expression of protective genes specific for each of the imposed stresses (Ouyang et al. 2011). This specificity appears to result from the differential mechanisms of Yap1 activation imposed by the analyzed stress agents. The global analysis of the role of Yap1 in yeast response to benomyl induced stress had also highlighted the differences between the gene-sets up-regulated by Yap1 in response to ROS or to thiol-reactive compounds (Lucau-Danila et al. 2005). Genes required for the maintenance of redox balance were shown to be up-regulated in both cases, while specific genes such as SOD1 and CTT1, encoding the cytosolic superoxide dismutase and catalase, respectively, are only responsive to ROS. An interesting discovery from this study was that the promoter occupancy by Yap1, when activated by benomyl, increases in all the promoters of Yap1 targets genes, including highly up-regulated genes such as FLR1, but also non-responsive genes such as CTT1 and SOD1 (Lucau-Danila et al. 2005). This finding 


\begin{tabular}{|c|c|c|c|}
\hline Gene & $\begin{array}{l}\text { Binding } \\
\text { evidence }\end{array}$ & $\begin{array}{l}\text { Expression evidence } \\
\text { (under stress) }\end{array}$ & References \\
\hline \multicolumn{4}{|c|}{ Drug:H+ Antiporters } \\
\hline ATR1 & + & $\begin{array}{l}\text { Arsenic, Arsenite, } \\
\text { Hydrogen peroxide, } \\
\text { Nitric oxide, Selenite }\end{array}$ & $\begin{array}{l}\text { (Coleman et al. 1997; Harbison et al. } \\
\text { 2004; Haugen et al. 2004; Horan et al. } \\
\text { 2006; Kelley and Ideker 2009; Lucau- } \\
\text { Danila et al. 2005; Salin et al. 2008; } \\
\text { Thorsen et al. 2007; Workman et al. } \\
\text { 2006) }\end{array}$ \\
\hline AZR1 & + & Arsenic & (Haugen et al. 2004; Salin et al. 2008) \\
\hline DTR1 & + & - & (Salin et al. 2008) \\
\hline FLR1 & + & $\begin{array}{l}\text { Arsenic, Arsenite, } \\
\text { Benomyl, Diamide, } \\
\text { Diazaborine, } \\
\text { Diethylmaleate, } \\
\text { Hydrogen peroxide, } \\
\text { Hydroxyurea, } \\
\text { Methylmethane } \\
\text { sulfonate, Tert-butyl } \\
\text { hydroperoxide, } \\
\text { Selenite }\end{array}$ & $\begin{array}{l}\text { (Alarco et al. 1997; Brôco et al. 1999; } \\
\text { Dubacq et al. 2006; Haugen et al. 2004; } \\
\text { Jungwirth et al. 2000; Kelley and Ideker } \\
\text { 2009; Lucau-Danila et al. 2005; Nguyen } \\
\text { et al. 2001; Salin et al. 2008; Teixeira et } \\
\text { al. 2010; Teixeira et al. 2008; Tenreiro et } \\
\text { al. 2001; Thorsen et al. 2007; Workman } \\
\text { et al. 2006) }\end{array}$ \\
\hline QDR3 & - & $\begin{array}{l}\text { Spermine, } \\
\text { Spermidine }\end{array}$ & (Teixeira et al. 2011a) \\
\hline TPO1 & - & Benomyl & (Lucau-Danila et al. 2005) \\
\hline TPO2 & - & Arsenite & (Thorsen et al. 2007) \\
\hline TPO4 & - & Arsenic & (Haugen et al. 2004) \\
\hline YHK8 & + & Nitric oxide & $\begin{array}{l}\text { (Harbison et al. 2004; Horan et al. 2006; } \\
\text { Lee et al. 2002) }\end{array}$ \\
\hline \multicolumn{4}{|c|}{ Pleiotropic Drug Resistance ABC transporters } \\
\hline PDR5 & + & $\begin{array}{l}\text { Arsenite, Benomyl, } \\
\text { Hydrogen peroxide }\end{array}$ & $\begin{array}{l}\text { (Kelley and Ideker 2009; Lucau-Danila } \\
\text { et al. 2005; Salin et al. 2008; Thorsen et } \\
\text { al. 2007) }\end{array}$ \\
\hline PDR18 & + & 2,4-D & (Cabrito et al. 2011; Salin et al. 2008) \\
\hline SNQ2 & + & Arsenite, Benomyl & $\begin{array}{l}\text { (Harbison et al. 2004; Lee et al. 2002; } \\
\text { Lucau-Danila et al. 2005; Salin et al. } \\
\text { 2008; Thorsen et al. 2007; Workman et } \\
\text { al. 2006) }\end{array}$ \\
\hline YCF1 & + & $\begin{array}{l}\text { Arsenic, Cadmium, } \\
\text { Diazaborine }\end{array}$ & $\begin{array}{l}\text { (Haugen et al. 2004; Jungwirth et al. } \\
\text { 2000; Lucau-Danila et al. 2005; Salin et } \\
\text { al. 2008; Wemmie et al. 1994) }\end{array}$ \\
\hline
\end{tabular}

Table 1. S. cerevisiae multidrug resistance transporter encoding genes under the control of Yap1, according to the YEASTRACT database (www.yeastract.com). Whether there is evidence (+) or not (-) for Yap1 binding to the promoter regions of the selected genes is indicated. The stress conditions leading to target gene up-regulation under Yap1 control are also highlighted. Supporting references are provided. 
reinforces the possibility that the different mechanisms of Yap1 activation lead to diverse conformational changes which do not deeply affect Yap1 binding ability, but rather its action as a transcriptional activator, allowing this transcription factor to discriminate, among its target genes, those that should be up-regulated in each condition.
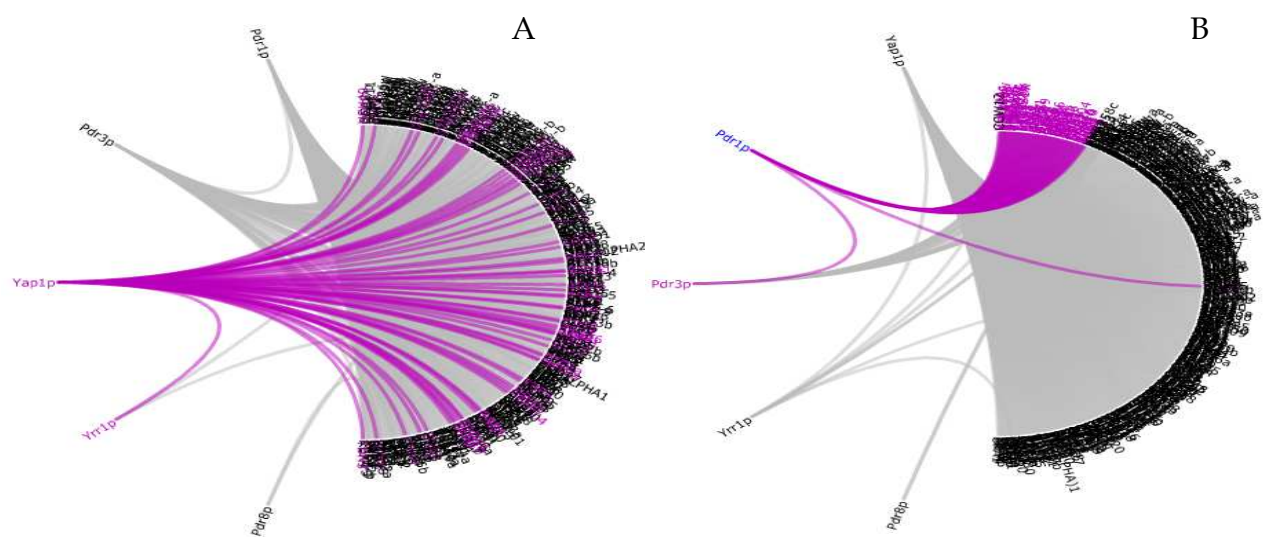

Fig. 2. Global overlapping between the Yap1 and the PDR regulatory networks. On the left, the participation of the Yap1 transcription factor in the regulation of around 18\% of the Pdr1 targets is highlighted, while the right panel emphasizes the role of Pdr1 in the regulation of about $15 \%$ of the Yap1 regulon. Both networks were built based on the information gathered in the YEASTRACT database (www.yeastract.com), considering only DNA-binding evidence for the establishment of transcriptional association between transcription factors and target genes.

\section{The role of the pdr network in oxidative stress response}

Since there is a clear role of Yap1 in MDR, the hypothesis that the PDR network may also play a role in oxidative stress seems logical. Although, to date there is no evidence supporting that the PDR network plays a clear role in the response to oxidative stress induced by ROS, several studies have highlighted the role of this multidrug resistance network in the response to pro-oxidant drugs and xenobiotics (Lelandais and Devaux). These include the agricultural fungicides mancozeb (Teixeira et al. 2010; Teixeira et al. 2008) and benomyl (Lucau-Danila et al. 2005), the herbicide 2,4-dichlorophenoxyacetic acid (Teixeira et al. 2007), the redox-cycling agent menadione and selenite (Salin et al. 2008). Indeed, in yeast cells exposed to pro-oxidants and metalloids, a cooperation between the transcription factors Pdr1/Pdr3 and Yap1, Rpn4 and Hsf1 in the modulation of oxidative stress response appears to exist.

In the particular case of the seletine stress response, microarray analysis was used to check the transcriptome-wide effect of the deletion of the transcription factor encoding genes YAP1, RPN4, PDR1 and PDR3. It was found that the absence of Pdr1 or Pdr3 affected the expression of around $20 \%$ of the Yap1 targets genes induced under selenite stress. These shared genes were found to include chemical stress response genes such as FLR1, as expected, but also a sub-group of oxidative stress responsive genes. When taking a global 
look at the information gathered in the YEASTRACT database (Abdulrehman et al. 2011; Monteiro et al. 2008; Teixeira et al. 2006), it becomes clear that around 15\% of the Yap1 target genes are also Pdr1 targets (Fig. 2B). Among these shared targets a small, but significant set of genes encoding direct antioxidant enzymes have been shown to be direct targets of the PDR transcription factors, including the cytosolic catalase Ctt1 (Devaux et al. 2002; Hikkel et al. 2003), and the alkyl hydroperoxide reductase Ahp1 (Larochelle et al. 2006) (Fig. 3).

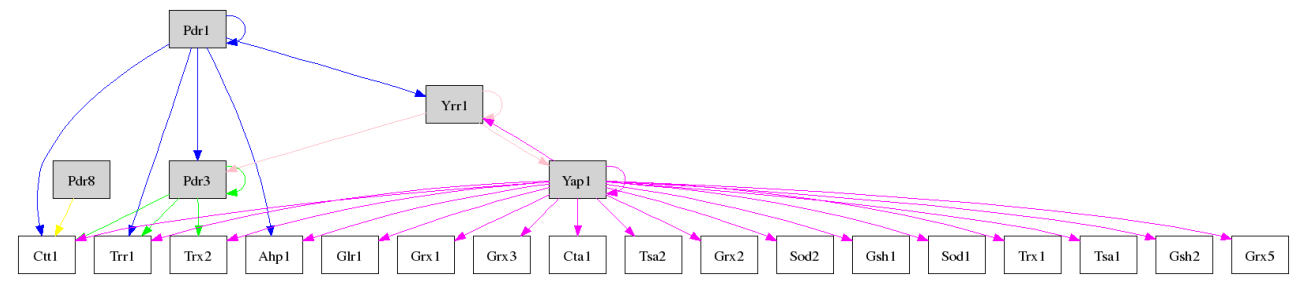

Fig. 3. The core oxidative stress response regulatory control, focused on the transcription factor Yap1 and on the yeast genes encoding antioxidant enzymes or proteins required for the maintenance of cellular redox balance. The role of the PDR network transcription factors in the regulation of these genes is displayed, based on the information gathered in the YEASTRACT database (www.yeastract.com).

In this context, it is also important to point out the specific role of Pdr3, but not of Pdr1, in the response to mitochondrial dysfunction (Devaux et al. 2002; Hallstrom and Moye-Rowley 2000), one of the main natural sources of oxidative imbalance. Indeed, upon the deletion of the mitochondrial genome, Pdr3 was seen to play a role in the activation of 14 , out of 54 , genes whose expression changes in these circumstances, placing Pdr3 as one of the transcription factors responsible for the retrograde response pathway (Devaux et al. 2002). Differently from what happens under chemical stress, upon mitochondrial dysfunction Pdr3 was seen to be post-translationally modified, but the exact nature of this modification was not clarified to date. The proposed role of this transcription factor in the response to mitochondrial dysfunction, as a controller of plasma membrane properties, still remains to be elucidated.

\section{Cross-talk between multidrug resistance control and oxidative stress response in pathogenic yeasts}

The study of multidrug resistance in pathogenic yeast species has been guided, to some extent, by the knowledge gathered for S. cerevisiae, as a model organism. A particularly close degree of similarity can be found when comparing this model organism with Candida glabrata, while the observations made for C. albicans and other Candida species reveal a lower conservation in terms of MDR regulation.

Clinical multiple antifungal drug resistance in C. albicans is mostly found to be based on the over-expression of the ABC multidrug efflux pumps encoded by CDR1 (Prasad et al. 1995) and CDR2 (Sanglard et al. 1997) genes, which share a high degree of homology with $S$. cerevisiae PDR5, and of the MFS drug: $\mathrm{H}^{+}$antiporter MDR1 (Goldway et al. 1995), a close homologue to $S$. cerevisiae FLR1 gene. FLU1, another C. albicans drug: $\mathrm{H}^{+}$antiporter encoding gene, was also found to confer fluconazole resistance, but to a lesser extent (Calabrese et al. 
2000). Interestingly, the regulation of these multidrug transporters shares some similarity to that of their homologues in budding yeast. The C. albicans transcription factor Tac1, belonging to the $S$. cerevisiae Pdr1/Pdr3 protein family, was found to be required for CDR1 and CDR2 up-regulation induced by the drug fluphenazine (Coste et al. 2004). Another Pdr1/Pdr3 homologous transcription factor, Mrr1, was found to control the expression of MDR1, in both fluconazole-resistant clinical isolates and in benomyl-or hydrogen peroxidechallenged cells (Morschhauser et al. 2007). Of particular interest, in the context of this review, is the fact that the Yap1 homologue from C. albicans, named Cap1, is also involved in multidrug resistance (Alarco et al. 1997; Alarco and Raymond 1999), controlling MDR1 expression, directly binding to its promoter region (Znaidi et al. 2009).

In C. glabrata, multidrug resistance relies mostly on the ABC drug efflux pumps CgCDR1 (a ScPDR5 homologue), CgPDH1/CgCDR2 (a ScPDR15 homologue) and CgSNQ2 (a ScSNQ2 homologue), but also on the drug-H+ antiporter CgFLR1 (Chen et al. 2007). In this pathogenic yeast a single homologue of the budding yeast transcription factors Pdr1/Pdr3, CgPdr1, appears to control antifungal drug resistance through its action as an activator of all of the above mentioned $\mathrm{ABC}$ transporter encoding genes. This role is not only seen in the response of laboratory strains to suddenly imposed stress, but also in azole-resistant clinical isolates (Torelli et al. 2008; Tsai et al. 2006). The role of other C. glabrata CgPdr1 homologues, such as CgYrm1, has not been inspected so far. The C. glabrata Yap1 homologue, Cgap1, has also been related to the control of multidrug resistance transporters. Specifically, it was found to be required for CgFLR1 up-regulation in response to benomyl-induced stress (Chen et al. 2007). Although this transcription factor was not seen to confer antifungal drug resistance its expression does increase $C$. glabrata tolerance to toxic concentrations of various oxidants and other xenobiotics (Chen et al. 2007). It is expectable that the understanding of the complex transcriptional regulation of MDR in this less well-studied organism will increase in the near future, guided by the huge amount of information that is being provided through genome-wide approaches. For example, microarray analysis revealed that ORF CAGLOG08624g, encoding a close homolog to the $S$. cerevisiae MFS-MDR transporter Qdr2 [T4, (Vargas et al. 2004)], is transcriptionally activated in response to fluconazole induced stress, in the dependency of the CgPdr1 transcription factor (Vermitsky and Edlind 2004). A more recent transcriptomics study showed that the expression of CgFLR1 and ORF CAGLOG03927g (a ScTPO1 homologue) genes is up-regulated in cells challenged with benomyl, under the control of the Cgap1 transcription factor (Lelandais et al. 2008). Although this subject has only now began to be unraveled in C. glabrata, current results already allow us to build a relatively small PDR network (Caudle et al.; Ferrari et al.; Lelandais et al. 2008; Tsai et al. 2006), including Cgap1, as depicted in Fig. 4.

Altogether, these results reinforce the notion that the transcriptional control of multidrug resistance and oxidative stress response are highly interconnected processes in yeasts and suggest that this crosstalk may be extended to other more complex eurakyotes.

\section{The combinatorial regulation of the multidrug transporter FIr1: A systems biology case-study}

The FLR1 gene, encoding a plasma membrane drug:H+ antiporter, was one of the first of its family to be characterized. Although it derives its name from FLuconazol Resistance (Alarco et al. 1997), Flr1 has been shown to confer resistance to a large number of chemically and 




Fig. 4. The PDR network in the human pathogen Candida glabrata, based on the results of the few global studies carried so far on the subject (Caudle et al.; Ferrari et al.; Lelandais et al. 2008; Tsai et al. 2006). The role of the transcription factors CgPdr1 and Cgap1 in the regulation of the genes encoding predicted drug:H+ antiporters of the MFS (upper box) or multidrug resistance $\mathrm{ABC}$ efflux pumps (lower box) is highlighted.

structurally unrelated xenobiotics and drugs, including cycloheximide, 4-nitroquinoline-1oxide (4-NQO), benomyl, methotrexate, diazaborine, cerulenin, diamide, diethylmaleate, menadione, paracetamol and mancozeb (Alarco et al. 1997; Brôco et al. 1999; Jungwirth et al. 2000; Srikanth et al. 2005; Teixeira et al. 2008). Unlike many of the DHA encoding genes (SáCorreia et al. 2009), FLR1 is highly induced at the transcriptional level when yeast cells are exposed to the stresses this gene confers resistance to. This high responsiveness to stress, made FLR1 transcriptional control an attractive working model to study complex transcriptional regulation mechanisms. The first indication on FLR1 transcriptional control, came very early on, when FLR1 was identified as a Yap1 target in S. cerevisiae (Alarco et al. 1997). Upon Yap1 deletion, the up-regulation of FLR1, found to occur in yeast cells exposed to the fungicide benomyl, was seen to be completely abrogated (Brôco et al. 1999; Tenreiro et al. 2001). At the same time, maximal activation of FLR1 under benomyl stress was found to be dependent on the presence of an additional transcription factor, Pdr3 (Brôco et al. 1999; Tenreiro et al. 2001). Interestingly, FLR1 promoter region was found to include three putative Yap1-Responsive Elements (YRE1-3) (Fig. 6). In a detailed study of the role of each of these predicted binding sites, Nguyen and co-workers found that the three binding sites were functional, but that their relative importance depends on the imposed stress (Nguyen et al. 2001). Indeed, using site-directed mutagenesis to remove each of the Yap1-binding sites, YRE3 (-364) was found to be the major player in FLR1 activation under stress imposed by benomyl and diethylmaleate. However, YRE2 (-167) becomes the most significant YRE in FLR1 up-regulation induced by hydrogen peroxide, diamide and tert-butyl hydroperoxide. Finally, all three YREs are equally important to assure full activation of FLR1 in response to 
methylmethane sulfonate (Nguyen et al. 2001). This finding may relate to the fact that at least some of these stresses lead to different Yap1 conformations, which in term may change the transcription factor's affinity towards the possible variations of the Yap1-Responsive Element. Furthermore, the fact that YRE3 is responsible for $90 \%$ of the FLR1 up-regulation induced by benomyl, may relate to the fact this Yap1-binding site is in the proximity of the predicted Pdr1/Pdr3-Responsive Element. The possibility that the binding of Pdr3 to the FLR1 promoter facilitates Yap1 activity in the nearby YRE3 was then proposed by Tenreiro et al (Tenreiro et al. 2001).

Additional clues to unveil the complete FLR1 regulatory network came from functional genomics approaches. Using all available information gathered in the YEASTRACT database, based on either microarray or ChIP-on-chip analysis, it is now possible to predict that a very complex regulatory network including 15 transcription factors is responsible for FLR1 regulation (Fig. 5). In an attempt to understand whether this network could be working together to control FLR1 expression in a single stress condition, an FLR1 promoterlacZ fusion was used to study FLR1 expression under stress induced by the fungicide mancozeb, in the presence or absence of each of the transcription factors found to occur in the predictive network. FLR1 activation in yeast cells exposed to mancozeb was found to depend upon Yap1 and Pdr3, as previously registered under benomyl stress. However, two additional transcription factors were found to be required for mancozeb-induced FLR1 maximal activation: Yrr1, one of the transcription factors controlling the PDR network, and Rpn4, a proteasomal gene regulator (Teixeira et al. 2008).



Fig. 5. Network of transcription factors documented as affecting FLR1 expression, as retrieved from the YEASTRACT database (www.yeastract.com). The L-shaped box indicates the sub-network found to affect FLR1 up-regulation occurring in yeast cells challenged with the fungicide mancozeb (Teixeira et al. 2008). 
Given the fact that it is becoming increasingly clear that transcriptional regulation is far more complex that initially foreseen, the use of systems biology approaches seems to be the only way to pursue the goal of understanding such biological processes in all their depth. Indeed, Systems Biology aims at understanding living processes as systems of multiple interacting components, preferably at a genome-wide scale, and through the combination of experimental and computational approaches. Such an approach was undertaken to further analyze the FLR1 regulatory network. The profiles of FLR1, YAP1, PDR3, YRR1 and RPN4 transcript levels were registered during the period of adaptation of a yeast cell population to stress imposed by the fungicide mancozeb, in wild-type cells and in mutants devoid of each of the four transcription factors (Teixeira et al. 2008). This information was used to build a mathematical description of the FLR1 network (Teixeira et al. 2010), taking advantage of the freely available GNA software (de Jong et al. 2003). This modeling approach allowed the testing of new hypothesis in silico (Monteiro et al. 2011), providing guidance for the design of further experimental work (Teixeira et al. 2010). The comparison between simulated and experimentally obtained results led to a refined understanding of the network, including the realization that a fifth still unidentified transcription factor, denominated Factor $X$, has to be included in the network to fully explain the observed transcriptional profiles (Fig. 6). Furthermore, combined results suggested that Yap1 and Yrr1 may function together, eventually working as a heterodimer, in the co-regulation of their shared target genes, which include the multidrug transporter encoding genes FLR1, AZR1 and SNQ2 and the transcription factor encoding genes PDR3, YRR1 and RPN4 (Teixeira et al. 2010).

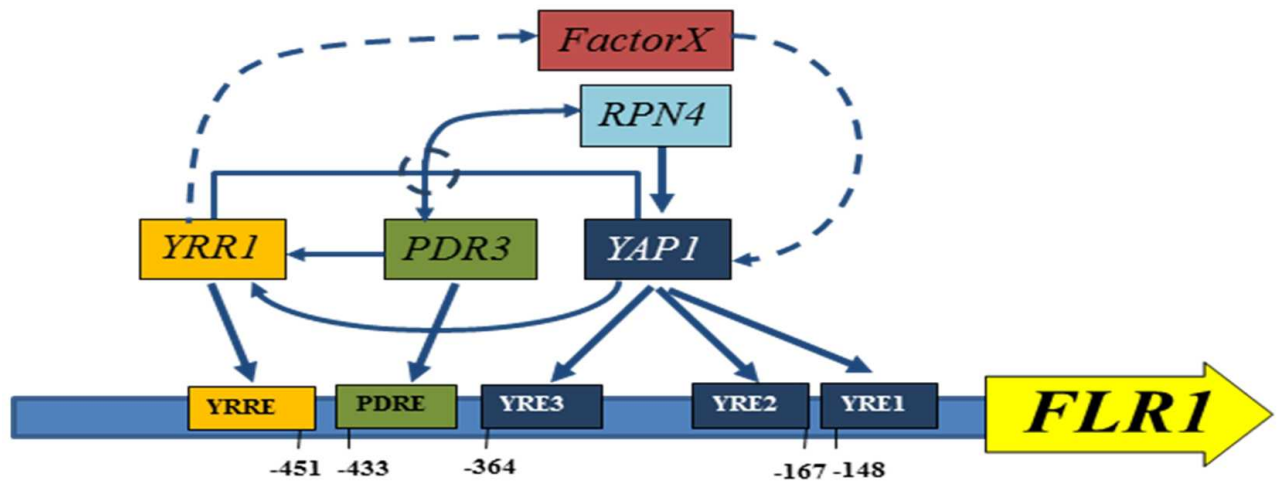

Fig. 6. FLR1 regulatory network structure, found to be functional in yeast cells exposed to mancozeb stress, as obtained from the combination of computational and experimental approaches described by Teixeira et al (Monteiro et al. 2011; Teixeira et al. 2010). Dashed arrows indicate the new aspects of the network suggested by the used systems biology approach that are still to be validated.

Studies in C. glabrata and C. albicans showed that the ScFLR1 homologues CgFLR1 and CaMDR1 are regulated by Yap1p homologs in either species (Chen et al. 2007; Znaidi et al. 2009). Whether the C. glabrata homologs of the S. cerevisiae Yrr1 and Rpn4 transcription factors also play a role in CgFLR1 regulation is still an open question. An interesting clue comes from the fact that the C. albicans homologue of ScPdr3, CaMrr1, is also required for full CaMDR1 activation (Morschhauser et al. 2007). These results strongly suggest that there 
may be a significant degree of conservation between multidrug resistance control in these related yeast species.

The current version of the FLR1 regulatory network is small but intricate. We believe that it is a good example of how complex transcription control in eukaryotes may be. Furthermore, it provides a good platform for further studies on the connection between oxidative stress response and two additional biological processes: multidrug resistance and protein degradation through the proteasome.

\section{Conclusion and perspectives}

Multidrug resistance control and stress response, in particular oxidative stress response, are now recognized as two complex cellular processes that coexist and interplay to allow cells to thrive in harsh environments. This chapter highlights current knowledge on the cross-talk between oxidative stress and MDR regulation in the model eukaryote $S$. cerevisiae. It emphasizes that, although being more focused on their canonical roles, both Yap1 and the PDR regulators play important functions in the regulation of multidrug efflux pumps and antioxidant enzymes, respectively.

At the moment, the logical explanation for this cross-talk appears to lie on the fact that many drugs and other xenobiotics may exert pro-oxidant effects, thus activating both multidrug resistance and oxidative stress response pathways. A question that still remains to be answered relates to why multidrug transporters should be controlled by Yap1 and more specifically what might be their role, if any, in oxidative stress response. For the single case of the vacuolar membrane ABC transporter Ycf1, there seems to be a possible connection. Ycf1, a close homologue to the human MRP1 multidrug transporter, confers resistance to chemical stress, including metal ions, antimonite, arsenite, 1-chloro-2,4-dinitrobenzene and diazaborine. The role of Ycf1 in metal ion resistance was further explored and this transporter was found to mediate the vacuolar compartmentalization of S-glutathione conjugates (Li et al. 1996). Glutathione, whose concentration is controlled by Yap1, through the regulation of the glutathione synthetase encoding gene GSH1, plays a crucial role in the maintenance of the intracellular redox potential. It is thus reasonable to think that the oxidative stress response regulator Yap1 may coordinately control the expression of GSH1 and YCF1, to assure the maintenance of the physiological concentration of free cytosolic reduced glutathione. As for the remaining multidrug transporters controlled by Yap1, such a close link between drug detoxification and oxidative stress response remains to be established. Nonetheless, it is reasonable to think that, since many of the natural chemical stress inducers are also capable of unbalancing the cellular redox state, the oxidative stress signaling would also control the expression of membrane transporters capable of relieving the cell from the exogenous source of oxidative stress. Interestingly, in bacterial systems a rather similar coordination of the response to xenobiotics and oxidants can also be found, under the control of the SoxRS regulon. Indeed, the E. coli SoxRS transcription factor controls the expression of both antioxidant enzymes and also of, at least, the outer membrane protein (porin) F, OmpF, suggested to play a role in reducing cell membrane permeability towards ROS or ROS-generating compounds (reviewed in (Lushchak 2011)).

Altogether, the results reviewed herein also highlight the fact that transcriptional control is much more complex than initially foreseen. Indeed, we come to realize that it is not possible 
to study individual phenomena, as if there was no influence from the surrounding, and even interconnected, cellular processes. The compilation of all the regulatory associations identified, so far, in S. cerevisiae, deposited in the YEASTRACT database (Abdulrehman et al. 2011; Monteiro et al. 2008; Teixeira et al. 2006), reveals that there are more than 48,000 regulatory associations between transcription factors and target genes. This number, which indicates that, on average, each yeast gene is controlled by at least 8 different transcription factors, rises up to nearly 375,000, when making in silico predictions based on the occurrence of transcription factor recognition sequences in the yeast promoter regions. Given this high degree of complexity, the study of biological networks using the new interdisciplinary approaches of Systems Biology seems to be the most suitable way to tackle this issue. The small, but intricate case-study explored herein, focused on the S. cerevisiae FLR1 regulatory network, suggests that the use of computer modeling, as a systems biology tool, will be crucial to increase our understanding of the cross-talk between regulatory networks.

\section{Acnowledgements}

Work on transcriptional control of yeast multidrug resistance transporters in our laboratory is being financially supported by FEDER and Fundação para a Ciência e Tecnologia (FCT) (contracts PTDC/BIO/72063/2006, PTDC/BIA-MIC/72577/2006 and PTDC/EBB$\mathrm{BIO} / 119356 / 2010)$.

\section{References}

Abdulrehman D, Monteiro PT, Teixeira MC, Mira NP, Lourenco AB, Dos Santos SC, Cabrito TR, Francisco AP, Madeira SC, Aires RS, Oliveira AL, Sá-Correia I, Freitas AT (2011) YEASTRACT: providing a programmatic access to curated transcriptional regulatory associations in Saccharomyces cerevisiae through a web services interface. Nucleic Acids Res, 39, pp. D136-140

Alarco AM, Balan I, Talibi D, Mainville N, Raymond M (1997) AP1-mediated multidrug resistance in Saccharomyces cerevisiae requires FLR1 encoding a transporter of the major facilitator superfamily. J Biol Chem, 272, pp. 19304-19313

Alarco AM, Raymond M (1999) The bZip transcription factor Cap1p is involved in multidrug resistance and oxidative stress response in Candida albicans. J Bacteriol, 181, pp. $700-708$

Azevedo D, Tacnet F, Delaunay A, Rodrigues-Pousada C, Toledano MB (2003) Two redox centers within $\mathrm{Yap} 1$ for $\mathrm{H}_{2} \mathrm{O}_{2}$ and thiol-reactive chemicals signaling. Free Radic Biol Med, 35, pp. 889-900

Balzi E, Chen W, Ulaszewski S, Capieaux E, Goffeau A (1987) The multidrug resistance gene PDR1 from Saccharomyces cerevisiae. J Biol Chem, 262, pp. 16871-16879

Balzi E, Goffeau A (1995) Yeast multidrug resistance: the PDR network. J Bioenerg Biomembr, 27, pp. 71-76

Balzi E, Wang M, Leterme S, Van Dyck L, Goffeau A (1994) PDR5, a novel yeast multidrug resistance conferring transporter controlled by the transcription regulator PDR1. J Biol Chem, 269, pp. 2206-2214

Brôco N, Tenreiro S, Viegas CA, Sá-Correia I (1999) FLR1 gene (ORF YBR008c) is required for benomyl and methotrexate resistance in Saccharomyces cerevisiae and its 
benomyl-induced expression is dependent on Pdr3 transcriptional regulator. Yeast, 15, pp. $1595-1608$

Cabrito TR, Teixeira MC, Singh A, Prasad R, Sá-Correia I (2011) The yeast ABC transporter Pdr18 (ORF YNR070w) controls plasma membrane sterol composition, playing a role in multidrug resistance. Biochem J, 440, 195-202

Calabrese D, Bille J, Sanglard D (2000) A novel multidrug efflux transporter gene of the major facilitator superfamily from Candida albicans (FLU1) conferring resistance to fluconazole. Microbiology, 146 ( Pt 11), pp. 2743-2754

Caudle KE, Barker KS, Wiederhold NP, Xu L, Homayouni R, Rogers PD Genomewide expression profile analysis of the Candida glabrata Pdr1 regulon. Eukaryot Cell, 10, pp. 373-383

Chen KH, Miyazaki T, Tsai HF, Bennett JE (2007) The bZip transcription factor Cgap1p is involved in multidrug resistance and required for activation of multidrug transporter gene CgFLR1 in Candida glabrata. Gene, 386, pp. 63-72

Coleman ST, Tseng E, Moye-Rowley WS (1997) Saccharomyces cerevisiae basic region-leucine zipper protein regulatory networks converge at the ATR1 structural gene. J Biol Chem, 272, pp. 23224-23230

Coste AT, Karababa M, Ischer F, Bille J, Sanglard D (2004) TAC1, transcriptional activator of CDR genes, is a new transcription factor involved in the regulation of Candida albicans ABC transporters CDR1 and CDR2. Eukaryot Cell, 3, pp. 1639-1652

de Jong H, Geiselmann J, Hernandez C, Page M (2003) Genetic Network Analyzer: qualitative simulation of genetic regulatory networks. Bioinformatics, 19, pp. 336-344

Decottignies A, Lambert L, Catty P, Degand H, Epping EA, Moye-Rowley WS, Balzi E, Goffeau A (1995) Identification and characterization of Snq2, a new multidrug ATP binding cassette transporter of the yeast plasma membrane. J Biol Chem, 270, pp. 18150-18157

Delaunay A, Isnard AD, Toledano MB (2000) H2O2 sensing through oxidation of the Yap1 transcription factor. EMBO J, 19, pp. 5157-5166

DeRisi J, van den Hazel B, Marc P, Balzi E, Brown P, Jacq C, Goffeau A (2000) Genome microarray analysis of transcriptional activation in multidrug resistance yeast mutants. FEBS Lett, 470, pp. 156-160

Devaux F, Carvajal E, Moye-Rowley S, Jacq C (2002) Genome-wide studies on the nuclear PDR3-controlled response to mitochondrial dysfunction in yeast. FEBS Lett, 515, pp. $25-28$

Dias PJ, Teixeira MC, Telo JP, Sá-Correia I (2010) Insights into the mechanisms of toxicity and tolerance to the agricultural fungicide mancozeb in yeast, as suggested by a chemogenomic approach. OMICS, 14, pp. 211-227

do Valle Matta MA, Jonniaux JL, Balzi E, Goffeau A, van den Hazel B (2001) Novel target genes of the yeast regulator Pdr1p: a contribution of the TPO1 gene in resistance to quinidine and other drugs. Gene, 272, pp. 111-119

Dubacq C, Chevalier A, Courbeyrette R, Petat C, Gidrol X, Mann C (2006) Role of the iron mobilization and oxidative stress regulons in the genomic response of yeast to hydroxyurea. Mol Genet Genomics, 275, pp. 114-124

Ferrari S, Sanguinetti M, Torelli R, Posteraro B, Sanglard D Contribution of CgPDR1regulated genes in enhanced virulence of azole-resistant Candida glabrata. PLoS One, 6, pp. e17589 
Goffeau A, Barrell BG, Bussey H, Davis RW, Dujon B, Feldmann H, Galibert F, Hoheisel JD, Jacq C, Johnston M, Louis EJ, Mewes HW, Murakami Y, Philippsen P, Tettelin H, Oliver SG (1996) Life with 6000 genes. Science, 274, pp. 546, 563-547

Goldway M, Teff D, Schmidt R, Oppenheim AB, Koltin Y (1995) Multidrug resistance in Candida albicans: disruption of the BENr gene. Antimicrob Agents Chemother, 39, pp. $422-426$

Hahn JS, Neef DW, Thiele DJ (2006) A stress regulatory network for co-ordinated activation of proteasome expression mediated by yeast heat shock transcription factor. $\mathrm{Mol}$ Microbiol, 60, pp. 240-251

Hallstrom TC, Moye-Rowley WS (2000) Multiple signals from dysfunctional mitochondria activate the pleiotropic drug resistance pathway in Saccharomyces cerevisiae. J Biol Chem, 275, pp. 37347-37356

Harbison CT, Gordon DB, Lee TI, Rinaldi NJ, Macisaac KD, Danford TW, Hannett NM, Tagne JB, Reynolds DB, Yoo J, Jennings EG, Zeitlinger J, Pokholok DK, Kellis M, Rolfe PA, Takusagawa KT, Lander ES, Gifford DK, Fraenkel E, Young RA (2004) Transcriptional regulatory code of a eukaryotic genome. Nature, 431, pp. 99-104

Haugen AC, Kelley R, Collins JB, Tucker CJ, Deng C, Afshari CA, Brown JM, Ideker T, Van Houten B (2004) Integrating phenotypic and expression profiles to map arsenicresponse networks. Genome Biol, 5, pp. R95

Hayes JD, Wolf CR (1997) Molecular genetics of drug resistance. In: Modern Genetics v. 3:Amsterdam, the Netherlands: Harwood Academic.

Hikkel I, Lucau-Danila A, Delaveau T, Marc P, Devaux F, Jacq C (2003) A general strategy to uncover transcription factor properties identifies a new regulator of drug resistance in yeast. J Biol Chem, 278, pp. 11427-11432

Horan S, Bourges I, Meunier B (2006) Transcriptional response to nitrosative stress in Saccharomyces cerevisiae. Yeast, 23, pp. 519-535

Ikner A, Shiozaki K (2005) Yeast signaling pathways in the oxidative stress response. Mutat Res, 569, pp. 13-27

Jungwirth H, Kuchler K (2006) Yeast ABC transporters-- a tale of sex, stress, drugs and aging. FEBS Lett, 580, pp. 1131-1138

Jungwirth H, Wendler F, Platzer B, Bergler H, Hogenauer G (2000) Diazaborine resistance in yeast involves the efflux pumps Ycf1p and Flr1p and is enhanced by a gain-offunction allele of gene YAP1. Eur J Biochem, 267, pp. 4809-4816

Kelley R, Ideker T (2009) Genome-wide fitness and expression profiling implicate Mga2 in adaptation to hydrogen peroxide. PLoS Genet, 5, pp. e1000488

Larochelle M, Drouin S, Robert F, Turcotte B (2006) Oxidative stress-activated zinc cluster protein Stb5 has dual activator/repressor functions required for pentose phosphate pathway regulation and NADPH production. Mol Cell Biol, 26, pp. 6690-6701

Le Crom S, Devaux F, Marc P, Zhang X, Moye-Rowley WS, Jacq C (2002) New insights into the pleiotropic drug resistance network from genome-wide characterization of the YRR1 transcription factor regulation system. Mol Cell Biol, 22, pp. 2642-2649

Lee TI, Rinaldi NJ, Robert F, Odom DT, Bar-Joseph Z, Gerber GK, Hannett NM, Harbison CT, Thompson CM, Simon I, Zeitlinger J, Jennings EG, Murray HL, Gordon DB, Ren B, Wyrick JJ, Tagne JB, Volkert TL, Fraenkel E, Gifford DK, Young RA (2002) Transcriptional regulatory networks in Saccharomyces cerevisiae. Science, 298, pp. 799-804 
Lelandais G, Devaux F (2010) Comparative functional genomics of stress responses in yeasts. OMICS, 14, pp. 501-515

Lelandais G, Tanty V, Geneix C, Etchebest C, Jacq C, Devaux F (2008) Genome adaptation to chemical stress: clues from comparative transcriptomics in Saccharomyces cerevisiae and Candida glabrata. Genome Biol, 9, pp. R164

Li ZS, Szczypka M, Lu YP, Thiele DJ, Rea PA (1996) The yeast cadmium factor protein (YCF1) is a vacuolar glutathione S-conjugate pump. J Biol Chem, 271, pp. 6509-6517

Lucau-Danila A, Delaveau T, Lelandais G, Devaux F, Jacq C (2003) Competitive promoter occupancy by two yeast paralogous transcription factors controlling the multidrug resistance phenomenon. J Biol Chem, 278, pp. 52641-52650

Lucau-Danila A, Lelandais G, Kozovska Z, Tanty V, Delaveau T, Devaux F, Jacq C (2005) Early expression of yeast genes affected by chemical stress. Mol Cell Biol, 25, pp. $1860-1868$

Lushchak VI (2011) Adaptive response to oxidative stress: Bacteria, fungi, plants and animals. Comp Biochem Physiol C Toxicol Pharmacol, 153, pp. 175-190

Monteiro PT, Dias PJ, Ropers D, Oliveira AL, Sá-Correia I, Teixeira MC, Freitas AT (2011) Qualitative modeling and formal verification of the FLR1 gen mancozeb response in Sacharomyces cerevisiae. IET Systems Biology, 5, pp.308-316

Monteiro PT, Mendes ND, Teixeira MC, d'Orey S, Tenreiro S, Mira NP, Pais H, Francisco AP, Carvalho AM, Lourenco AB, Sá-Correia I, Oliveira AL, Freitas AT (2008) YEASTRACT-DISCOVERER: new tools to improve the analysis of transcriptional regulatory associations in Saccharomyces cerevisiae. Nucleic Acids Res, 36, pp. D132-136

Morschhauser J, Barker KS, Liu TT, Bla BWJ, Homayouni R, Rogers PD (2007) The transcription factor Mrr1p controls expression of the MDR1 efflux pump and mediates multidrug resistance in Candida albicans. PLoS Pathog, 3, pp. e164

Nguyen DT, Alarco AM, Raymond M (2001) Multiple Yap1p-binding sites mediate induction of the yeast major facilitator FLR1 gene in response to drugs, oxidants, and alkylating agents. J Biol Chem, 276, pp. 1138-1145

Ouyang X, Tran QT, Goodwin S, Wible RS, Sutter CH, Sutter TR (2011) Yap1 activation by $\mathrm{H}_{2} \mathrm{O}_{2}$ or thiol-reactive chemicals elicits distinct adaptive gene responses. Free Radic Biol Med, 50, pp. 1-13

Owsianik G, Balzi 1 L, Ghislain M (2002) Control of $26 \mathrm{~S}$ proteasome expression by transcription factors regulating multidrug resistance in Saccharomyces cerevisiae. Mol Microbiol, 43, pp. 1295-1308

Prasad R, De Wergifosse P, Goffeau A, Balzi E (1995) Molecular cloning and characterization of a novel gene of Candida albicans, CDR1, conferring multiple resistance to drugs and antifungals. Curr Genet, 27, pp. 320-329

Rodrigues-Pousada C, Menezes RA, Pimentel C (2010) The Yap family and its role in stress response. Yeast, 27, pp. 245-258

Sá-Correia I, Santos S, Teixeira M, Cabrito T, Mira N (2009) Drug: $\mathrm{H}^{+}$antiporters in chemical stress response in yeast. Trends Microbiol, 17, pp. 22-31

Salin H, Fardeau V, Piccini E, Lelandais G, Tanty V, Lemoine S, Jacq C, Devaux F (2008) Structure and properties of transcriptional networks driving selenite stress response in yeasts. BMC Genomics, 9, pp. 333 
Sanglard D, Ischer F, Monod M, Bille J (1997) Cloning of Candida albicans genes conferring resistance to azole antifungal agents: characterization of $C D R 2$, a new multidrug ABC transporter gene. Microbiology, 143 (Pt 2), pp. 405-416

Saunders GW, Rank GH (1982) Allelism of pleiotropic drug resistance in Saccharomyces cerevisiae. Can J Genet Cytol, 24, pp. 493-503

Semchyshyn HM, Abrat OB, Miedzobrodzki J, Inoue Y, Lushchak VI (2011) Acetate but not propionate induces oxidative stress in bakers' yeast Saccharomyces cerevisiae. Redox Rep, 16, pp. 15-23

Srikanth CV, Chakraborti AK, Bachhawat AK (2005) Acetaminophen toxicity and resistance in the yeast Saccharomyces cerevisiae. Microbiology, 151, pp. 99-111

Teixeira MC, Cabrito TR, Hanif ZM, Vargas RC, Tenreiro S, Sá-Correia I (2011a) Yeast response and tolerance to polyamine toxicity involving the drug: $\mathrm{H}^{+}$antiporter Qdr3 and the transcription factors Yap1 and Gcn4. Microbiology, 157, pp. 945-956

Teixeira MC, Dias PJ, Monteiro PT, Sala A, Oliveira AL, Freitas AT, Sá-Correia I (2010) Refining current knowledge on the yeast FLR1 regulatory network by combined experimental and computational approaches. Mol Biosyst, 6, pp. 2471-2481

Teixeira MC, Dias PJ, Simoes T, Sá-Correia I (2008) Yeast adaptation to mancozeb involves the up-regulation of FLR1 under the coordinate control of Yap1, Rpn4, Pdr3, and Yrr1. Biochem Biophys Res Commun, 367, pp. 249-255

Teixeira MC, Duque P, Sá-Correia I (2007) Environmental genomics: mechanistic insights into toxicity of and resistance to the herbicide 2,4-D. Trends Biotechnol, 25, pp. 363-370

Teixeira MC, Mira NP, Sá-Correia I (2011b) A genome-wide perspective on the response and tolerance to food-relevant stresses in Saccharomyces cerevisiae. Curr Opin Biotechnol, 22 , pp. $150-156$

Teixeira MC, Monteiro P, Jain P, Tenreiro S, Fernandes AR, Mira NP, Alenquer M, Freitas AT, Oliveira AL, Sá-Correia I (2006) The YEASTRACT database: a tool for the analysis of transcription regulatory associations in Saccharomyces cerevisiae. Nucleic Acids Res, 34, pp. D446-451

Teixeira MC, Sá-Correia I (2002) Saccharomyces cerevisiae resistance to chlorinated phenoxyacetic acid herbicides involves Pdr1p-mediated transcriptional activation of TPO1 and PDR5 genes. Biochem Biophys Res Commun, 292, pp. 530-537

Teixeira MC, Telo JP, Duarte NF, Sá-Correia I (2004) The herbicide 2,4dichlorophenoxyacetic acid induces the generation of free-radicals and associated oxidative stress responses in yeast. Biochem Biophys Res Commun, 324, pp. 1101-1107

Tenreiro S, Fernandes AR, Sá-Correia I (2001) Transcriptional activation of FLR1 gene during Saccharomyces cerevisiae adaptation to growth with benomyl: role of Yap1p and Pdr3p. Biochem Biophys Res Commun, 280, pp. 216-222

Thakur JK, Arthanari H, Yang F, Pan SJ, Fan X, Breger J, Frueh DP, Gulshan K, Li DK, Mylonakis E, Struhl K, Moye-Rowley WS, Cormack BP, Wagner G, Naar AM (2008) A nuclear receptor-like pathway regulating multidrug resistance in fungi. Nature, 452, pp. 604-609

Thorsen M, Lagniel G, Kristiansson E, Junot C, Nerman O, Labarre J, Tamas MJ (2007) Quantitative transcriptome, proteome, and sulfur metabolite profiling of the Saccharomyces cerevisiae response to arsenite. Physiol Genomics, 30, pp. 35-43 
Torelli R, Posteraro B, Ferrari S, La Sorda M, Fadda G, Sanglard D, Sanguinetti M (2008) The ATP-binding cassette transporter-encoding gene CgSNQ2 is contributing to the CgPDR1-dependent azole resistance of Candida glabrata. Mol Microbiol, 68, pp. 186-201

Tsai HF, Krol AA, Sarti KE, Bennett JE (2006) Candida glabrata PDR1, a transcriptional regulator of a pleiotropic drug resistance network, mediates azole resistance in clinical isolates and petite mutants. Antimicrob Agents Chemother, 50, pp. 1384-1392

Vargas RC, Tenreiro S, Teixeira MC, Fernandes AR, Sá-Correia I (2004) Saccharomyces cerevisiae multidrug transporter Qdr2p (Yil121wp): localization and function as a quinidine resistance determinant. Antimicrob Agents Chemother, 48, pp. 2531-2537

Vermitsky JP, Edlind TD (2004) Azole resistance in Candida glabrata: coordinate upregulation of multidrug transporters and evidence for a Pdr1-like transcription factor. Antimicrob Agents Chemother, 48, pp. 3773-3781

Wemmie JA, Szczypka MS, Thiele DJ, Moye-Rowley WS (1994) Cadmium tolerance mediated by the yeast AP-1 protein requires the presence of an ATP-binding cassette transporter-encoding gene, YCF1. J Biol Chem, 269, pp. 32592-32597

Wendler F, Bergler H, Prutej K, Jungwirth H, Zisser G, Kuchler K, Hogenauer G (1997) Diazaborine resistance in the yeast Saccharomyces cerevisiae reveals a link between YAP1 and the pleiotropic drug resistance genes PDR1 and PDR3. J Biol Chem, 272, pp. 27091-27098

Workman CT, Mak HC, McCuine S, Tagne JB, Agarwal M, Ozier O, Begley TJ, Samson LD, Ideker T (2006) A systems approach to mapping DNA damage response pathways. Science, 312, pp. 1054-1059

Yan C, Lee LH, Davis LI (1998) Crm1p mediates regulated nuclear export of a yeast AP-1like transcription factor. EMBO J, 17, pp. 7416-7429

Znaidi S, Barker KS, Weber S, Alarco AM, Liu TT, Boucher G, Rogers PD, Raymond M (2009) Identification of the Candida albicans Cap1p regulon. Eukaryot Cell, 8, pp. 806-820 




\section{Oxidative Stress - Molecular Mechanisms and Biological Effects}

Edited by Dr. Volodymyr Lushchak

ISBN 978-953-51-0554-1

Hard cover, 362 pages

Publisher InTech

Published online 25, April, 2012

Published in print edition April, 2012

Since the discovery of free radicals in biological systems researchers have been highly interested in their interaction with biological molecules. Denoted in 1980, and due to fruitful results and ideas, oxidative stress is now appreciated by both basic and applied scientists as an enhanced steady state level of reactive oxygen species with wide range of biological effects. This book covers a wide range of aspects and issues related to the field of oxidative stress. The association between generation and elimination of reactive species and effects of oxidative stress are also addressed, as well as summaries of recent works on the signaling role of reactive species in eukaryotic organisms. The readers will gain an overview of our current understanding of homeostasis of reactive species and cellular processes they are involved in, as well as useful resources for further reading.

\section{How to reference}

In order to correctly reference this scholarly work, feel free to copy and paste the following:

Miguel C. Teixeira (2012). Complex Regulatory Interplay Between Multidrug Resistance and Oxidative Stress Response in Yeast: The FLR1 Regulatory Network as a Systems Biology Case-Study, Oxidative Stress Molecular Mechanisms and Biological Effects, Dr. Volodymyr Lushchak (Ed.), ISBN: 978-953-51-0554-1, InTech, Available from: http://www.intechopen.com/books/oxidative-stress-molecular-mechanisms-andbiological-effects/complex-regulatory-interplay-between-multidrug-resistance-and-oxidative-stress-responsein-yeast-th

\section{INTECH}

open science | open minds

\section{InTech Europe}

University Campus STeP Ri

Slavka Krautzeka 83/A

51000 Rijeka, Croatia

Phone: +385 (51) 770447

Fax: +385 (51) 686166

www.intechopen.com

\section{InTech China}

Unit 405, Office Block, Hotel Equatorial Shanghai

No.65, Yan An Road (West), Shanghai, 200040, China

中国上海市延安西路65号上海国际贵都大饭店办公楼405单元

Phone: +86-21-62489820

Fax: $+86-21-62489821$ 
(C) 2012 The Author(s). Licensee IntechOpen. This is an open access article distributed under the terms of the Creative Commons Attribution 3.0 License, which permits unrestricted use, distribution, and reproduction in any medium, provided the original work is properly cited. 